\title{
Researching Literacy and Numeracy Costs and Benefits: What is possible ${ }^{1}$
}

\author{
ROBYN HARTLEY and JACKIE HORNE
}

\begin{abstract}
Assessing the social and economic benefits of investing in adult literacy and numeracy and the costs of poor adult literacy and numeracy, is largely uncharted territory in Australia. Some interest was evident in the late 1980s leading up to International Literacy Year, 1990 (for example, Miltenyi 1989, Singh 1989, Hartley 1989); however, there has been little work done in the area since then, with the exception of recent studies concerned with financial literacy costs and benefits (Commonwealth Bank Foundation 2005). Assessing the benefits (returns) of workplace training in general has received some attention (for example Moy and McDonald 2000), although the role of literacy and numeracy is often implied rather than explored in any detail.

In contrast, there is a considerable body of relevant research emanating from the United States, Canada, the United Kingdom and some European countries. The release of data from the International Adult Literacy Survey (IALS) in the 1990s contributed to some of this research, as did policy developments for example, in the United Kingdom. The much greater use of IALS data in some other countries compared with Australia, seems to be related to a combination of factors in the overall policy and research environment for adult literacy and numeracy in each country.
\end{abstract}

\section{Mapping the costs and benefits}

While there is a very large body of literature linking related measures such as years of schooling or qualifications levels with a whole range of social and economic outcomes, it should be borne in mind that research that has examined the link between literacy and numeracy levels and economic and social outcomes, is still relatively new.

Contrary to prior expectations, however, the literature on frameworks and methodologies for estimating the costs associated with poor literacy, and the benefits of improving literacy is relatively wide and rich. For example, Hartley and Horne (2006) discuss the frameworks identified and the methodologies used in some detail, and at the same time they present information about a wide range of benefits and costs across quite diverse areas. 
In this paper, we first briefly outline factors that need to be considered in any framework for exploring social and economic benefits and costs, and summarise the main methodologies used. We then review the state of play, including relevant Australian research, in health literacy, consumer and financial literacy, and literacy and numeracy and small business. These areas were selected as worthy of follow up in Australia because of the robustness of international research, the range of methodologies available and a preliminary assessment of interest and potential for further development in Australia. We also include brief comments on family literacy research and research linking poor literacy and crime.

\section{The project}

This paper is based on findings from a recent project carried out by the Australian Council for Adult Literacy (ACAL) with funding from the Commonwealth government through the Adult Literacy National Project (http://literacynet.dest.gov.au/). The research drawn on here (Hartley and Horne 2006, hereafter referred to as the report) explored the frameworks and methodologies available for determining and measuring the benefits of improving adult literacy and numeracy and the costs of poor literacy and numeracy across what might be called various life domains. This was done through a literature review. The focus was on social domains such as health literacy, financial literacy and family literacy rather than traditional economic areas, although the latter literature was briefly reviewed. Consultations were then undertaken to explore in a preliminary way, the capacity and interest within Australia to move ahead with research into costs and benefits, and to identify the key issues that would need to be addressed in order to arrive at Australian estimates of benefits and costs. This work was intended to lay the ground-work for further research, however this has so far not eventuated.

Reflecting the content of the literature, the report does not explore in any detail the benefits and costs associated with adult numeracy (Hartley and Horne 2006). We acknowledge that while literacy and numeracy are frequently linked in the literature, poor numeracy has a different overall set of consequences to poor literacy, although some may be similar.

Nevertheless, the general frameworks identified and some of the representative methodologies which have been used to assess the benefits and costs of literacy, together with some of the general issues which emerged from the literature, are likely to be relevant and useful for exploring costs and benefits associated with numeracy. 


\section{Why research benefits and costs?}

Why focus on researching benefits and costs of literacy and numeracy? What are the potential benefits of doing so?

First, more reliable and useful information about individual, social and economic costs and benefits across various 'domains' of life and across the life span of individuals provides valuable information for literacy and numeracy policy development. Such information also both encourages and provides a basis for more robust evaluations of existing programs.

Second, recent research highlights the importance of pursuing a broad and integrated approach to language, literacy and numeracy policy (Beddie 2004, Wickert 2004). An increasingly diverse body of research shows that poor literacy and numeracy skills can have a pervasive impact on individuals (on their identity, health, family life and capacity to fully participate, socially and economically) and on communities, affecting the maintenance and growth of social capital. Rapid changes in information and other technologies are likely to continue to extend the range of literacies we need to function fully in society (see for example the review by Lonsdale and McGurry 2004). In addition, individuals are increasingly being expected to self-manage areas of their lives which require relatively high levels of literacy and numeracy. Negotiating individual employment contracts, making decisions about retirement income and managing chronic health conditions are just a few examples in the Australian context.

Literacy is thus a social as well as an economic issue, a matter for communities as well as for governments and educational policy makers. In light of this, there is a strong case for a much wider understanding of the social and economic benefits of improving literacy and numeracy and the costs of poor literacy and numeracy across different areas of life. In the broader arena, better community understanding has the potential for more diverse and widespread support for an increased allocation of resources for adult literacy and numeracy, and for increased government and private investment in adult literacy and numeracy.

Third, we would argue that more reliable information about a broad range of social and economic benefits and costs associated with adult literacy and numeracy would help to ensure that data from the Adult Literacy and Lifeskills Survey (ALLS), taking place in Australia in 2007, is put to the best strategic use. In relation to numeracy, a considerable amount of international effort, including input from Australia, went into developing an appropriate framework for directly measuring numeracy. However, the strategic use of the data needs to be encouraged and promoted amongst government departments, funding bodies, researchers, employers, teachers, community and other agencies. 
It is also the case, however, that identifying benefits and costs does not necessarily tell us how to go about reducing costs and enhancing benefits, except in the broadest terms. That is another issue, requiring cooperation among governments, literacy and numeracy practitioners, learners, researchers in diverse social areas, communities and other interested parties, working together and across areas where literacy has an impact.

\section{Measuring costs and benefits}

At the outset, it needs to be said that there are undeniable challenges in assessing and measuring benefits and costs associated with adult literacy and numeracy. The impacts (and therefore the costs and benefits) of multiple literacies are complex, cumulative, and interactive. Measurement of costs and benefits is rarely straightforward. This is particularly the case given that researchers from different backgrounds will approach the issue from a range of perspectives. It is therefore useful to refer to a number of measurement issues and concepts.

Economists typically approach the valuation of costs and benefits with their ideal standard of measuring everything in monetary terms. This allows them to undertake cost benefit analyses; that is, to compare the balance of costs and benefits over time, and to calculate a rate of return on an investment in a particular intervention, program or policy. Often, both the economic return (based on output or income) and the social return will be calculated. The social return has a wider base than the economic return and includes the monetary valuation of the costs and benefits to individuals, taxpayers and society at large.

It goes without saying that it is not always possible to value costs and benefits in monetary terms, especially in the fields of education and health. Depending on the research question and the extent of available data and techniques, together with the availability of funding for collecting new data on costs and benefits, the unit of measurement may be in monetary terms, for example the costs of health care. But more frequently, costs and benefits will be measured in another unit, for example rates of hospitalisation or smoking rates. Therefore, in exploring benefits of higher levels of literacy or the costs of poor literacy, a variety of approaches and estimation techniques have been used.

There are, of course, a whole host of issues to consider when it comes to reliably measuring costs and benefits and undertaking statistical analysis. In general, it is worth highlighting the need to control for other variables that may impact on the accurate measurement of the costs of poor literacy and numeracy and the benefits of improving them, as many socio-economic factors interact with literacy and outcomes of interest such as health. 


\section{General frameworks}

The most comprehensive available frameworks for investigating benefits and costs are concerned with adult learning, rather than with literacy per se. However, we would argue that they are useful for the concepts used, the types of research they have led to and the issues they raise. Overall, they indicate the importance of a multi-disciplinary approach to determining and measuring benefits and costs and the need to integrate so-called human capital and social capital approaches. Literacy and social capital is a burgeoning area of interest; however, the present focus is predominantly on social capital outcomes of literacy learning, rather than on measuring the social capital benefits and costs associated with literacy.

The frameworks reviewed suggest that attempts to measure the benefits and costs of literacy and numeracy need to consider a number of factors. While some may seem obvious, they are not always reflected in the relevant literature. Many of the factors listed below are drawn from the work of the Centre for Research into the Wider Benefits of Learning in the UK (see particularly Schuller, Bynner, Green, Blackwell, Hammond, Preston and Gough 2001 and Schuller, Preston, Hammond, BrassettGrundyand Bynner 2004).

- Benefits are both 'transforming' and 'sustaining'. The terms refer to the fact that learning (including literacy learning) may change people's lives in noticeable and measurable ways but the benefit may also be that learning supports, maintains and ensures that people and communities are able to keep being effective in doing what they do.

- Benefits are both individual and collective, affecting individual lives and interactions with others at all levels, as well as impacting on society as a whole. Sustaining and transforming benefits are possible at both an individual and collective level.

- $\quad$ Benefits are direct and indirect. Indirect benefits are often mediated by factors such as attitudes, values, self-esteem and confidence. In this way, literacy learning and proficiency are linked to areas such as health, family and social capital. For example, improved literacy may directly benefit the understanding of medical instructions and management of one's health, and indirectly lead to increased confidence in one's abilities and ultimately to increased psychological health.

- $\quad$ Benefits are cumulative; they build on previous experience.

- Benefits can be lost or reduced without continued practice; this relates back to the sustaining nature of literacy and numeracy benefits. 
- Benefits are dynamic; benefits gained in one domain impact on functioning in other domains, for example there is evidence to suggest that financial literacy impacts on health.

- Outcomes of learning, and this includes literacy, may be perceived (by the learner and/or others) as negative, at least in the short term. An example is the change in power balance in a relationship which may occur when a female partner learns new skills. This point raises questions beyond the scope of the review. However, it reminds us that what constitutes a benefit or a cost may be debatable and sometimes depends on one's point of view.

- $\quad$ Learning (and literacy) is a collective experience which has implications for personal and social identity.

- Benefits (and costs) are not 'all or nothing'. The 'degree' of benefit or cost will be affected by other and multiple factors, including the nature of initial and later (adult) learning. As far as the impacts of learning on well-being, mental health and effective coping are concerned, the wider benefits are maximised when 'pedagogy, curriculum, student mix and institutional context match the strengths, interests and needs of learners' (Schuller et al 2004, p37).

- Benefits and costs may vary for different groups of people. While some attention has been paid to differential benefits for example for older people, the question of whether and how benefits and costs vary, for example, across the life cycle and for women and men, needs to be included in the overall picture of benefits and costs.

\section{Methodologies}

A number of studies have used large datasets to measure the economic and social benefits of improving literacy skills or the costs of poor literacy to individuals and/or the economy and society. This includes the International Adult Literacy Survey (IALS) dataset and longitudinal cohort studies.

The IALS data has been used to examine the link between literacy and a number of economic variables, including labour market outcomes, earnings and the returns to different levels of education, and immigrant earnings. Analysis of IALS data (Williams 1999, quoted in Hagston 2002, Desjardins 2004) has also shown that receipt of welfare benefits, health, criminal activity, and community participation are linked with literacy skills and educational achievement. Health has been a particularly fruitful area of investigation. Although health outcomes were not directly measured in the IALS, analysis of IALS findings has shown that high levels of literacy are associated with better health outcomes, for example, higher life expectancy and healthier habits and lifestyles (OECD and Statistics Canada 2000). Similarly, Roberts and Fawcett's (1998) analysis of Canadian IALS data 
found that people with lower literacy levels were more likely to be at higher health risk, with an increased effect on senior citizens.

In Australia, Chiswick, Lee and Miller (2003) used data from the IALS to examine the effects on labour market outcomes of literacy, numeracy and schooling. It was found that approximately half of the total effect of schooling on labour force participation and on unemployment could be attributed to literacy and numeracy skills.

Most recently, data from the IALS was used by Coulombe, Tremblay and Marchand (2004) to identify a significant relationship between investments in human capital and a country's subsequent economic growth and labour productivity. The study is of particular interest because it was the first to identify a clear and significant association between a country's investment in human capital and its economic growth, and secondly, because it used a direct measure of skills, that is literacy levels, as measured by the IALS, to identify this link. Previous studies which focused on educational qualifications had failed to prove a link between human capital and economic growth. Coulombe et al (2004) concluded that a rise of one percent in a country's literacy score relative to the international average is associated with an eventual 2.5 percent relative rise in labour productivity and a 1.5 percent increase in GDP per head.

In the UK, two longitudinal cohort studies, the National Child Development Study which began in 1958 and the 1970 British Cohort Study, have been well used data sources for measuring non-economic and economic costs of poor literacy and numeracy, and the benefits to individuals and society of improving literacy and numeracy. This is no doubt because they include rich data on both economic and social outcomes.

A representative study, which measured both the economic and noneconomic impacts of improving adult literacy and numeracy skills, is that of Bynner, McIntosh, Vignoles, Dearden, Reed and van Reenen (2001). Using data from the National Child Development Study and the British Cohort Study, together with data from the UK Family Expenditure Survey and Family Resources Surveys, and using statistical modelling techniques, they found that individuals who increase their literacy and numeracy levels:

- improve their chances in the labour market, moving up the occupational status scale and resisting unemployment;

- $\quad$ suffer less from poor physical and mental health;

- $\quad$ are less likely to have children experiencing difficulty at school;

- $\quad$ are more likely to be active citizens, as shown by voting behaviour and expressing interest in politics, and

- $\quad$ are more liberal and less discriminatory in their attitudes. 
These effects persist after controlling for earlier family circumstances and educational achievement. Labour market effects were found to be stronger for the younger British Cohort Study cohort and the health and citizenship effects stronger for the older National Child Development Study cohort.

Within Australia, the impact of low school achievement in literacy and numeracy on unemployment has been measured using the Longitudinal Survey of Australian Youth (LSAY) dataset. Marks and Fleming (1998) found that low school achievement in literacy and numeracy was consistently associated with youth unemployment, with effects continuing through to the age of 33. Similarly, Gleeson (2005) used the LSAY dataset to examine the economic returns to training for adults with low levels of literacy and numeracy. The UK use of longitudinal cohort studies, especially studies which include a range of social and economic indicators, points to the possible use of similar longitudinal study data in Australia. This potential was explored in the consultations for the ACAL project.

\section{Health literacy}

Some useful frameworks for examining health literacy exist. One is Nutbeam's (1999) framework which describes functional, interactive and critical health literacy, and places health literacy in the broader arena of health promotion. Functional health literacy is broadly defined as the ability to read and comprehend medical information and instructions. Interactive health literacy refers to the development of personal skills that improve the capacity to act independently and improve both motivation and self confidence to act on advice received; critical health literacy refers to personal and community empowerment to act on the social and economic determinants of health.

A considerable amount of work on health literacy benefits and costs has been carried out and some comprehensive summaries and discussions of research exist (for example, Rootman and Ronson 2003, Berkman, DeWalt, Pignone, Sheridan, Lohr, Lux, Sutton, Swinson and Bonito 2004, Shohet 2004). However, while most studies to date have investigated either the benefits or costs of different levels of functional literacy from a medical perspective, there is growing recognition of the need to go beyond functional literacy.

Higher levels of health literacy have been linked to knowledge and understanding of such things as mammography, cervical cancer screening, emergency department discharge instructions, smoking, contraception, HIV, asthma, and post-operative care. Representative studies have found associations between lower literacy levels and for example, higher risk of hospitalisation, not having had a pap smear or mammogram in the previous two years, not having a flu injection, and higher rates of depression in 
various populations (Williams, Parker, Baker, Parikh, Pitkin, Coates and Nurss 1995, Berkman et al 2004).

Most attention has been paid to literacy and aspects of physical health or specific health issues such as asthma or diabetes, although the literature does include studies of 'mental health literacy' and 'depression literacy', broadly defined as knowledge, understanding and beliefs about mental health.

The extent to which findings can be generalised across different populations and different environments needs further investigation. Some studies (for example, Gillis and Quigley 2004) suggest that there are particular costs of poor health literacy in a rural environment.

Tools for assessing functional health literacy are available and have been relatively widely used. The most well-known are the Rapid Estimate of Adult Literacy in Medicine (REALM), Test of Functional Health Literacy in Adults (TOHFLA) or S-TOHFLA (shortened version of TOHFLA), and the Wide Range Achievement Test (WRAT). However they have some limitations and they have not yet been validated in a variety of cultural and social contexts. There are other important issues with the use of such tests, such as the ways in which they are administered and their potential negative impacts on people's self-esteem.

Some of the identified impacts of poor literacy are based on the knowledge and behaviour of individuals in the research sample rather than actual health outcomes. Only one study sought a monetary measurement of the costs of poor health literacy and found no association between health care costs and literacy. We did not identify studies to date which have valued the benefits of improving health literacy or of conducting a costbenefit analysis of investing in health literacy.

The cost of studies is an important consideration. They are generally not cheap, especially studies which involve face-to-face interviews to measure individuals' literacy levels and to collect data on the outcome in question.

In Australia, health literacy has not received the same attention as in some other countries. Nevertheless, there is evidence of increasing interest from some medical researchers, for example Buchbinder, Hall, Grant, Mylvaganam and Patrick (2001) have investigated the readability of patient information used by Australian rheumatologists; and Griffin, McKenna and Tooth (2003) have examined written health education material in the area of occupational therapy. While health literacy is being recognised as a factor which pre-disposes people to participate in screening programs, most existing research focuses on functional health literacy. However, there are also attempts to explore issues beyond functional literacy, to view communication between health professionals and patients more broadly, to take account of patients' understandings, expectations, beliefs and 
anticipations about the interaction, and to explore the "cultural competencies' of those involved (see, for example, www.ahrq.gov/browse/hlitix.htm\#Literacy).

\section{Financial literacy}

Of the reports that have formally defined financial literacy, Jacob, Hudson and Bush (2000:8) refer to:

personal financial knowledge and skills ... Financial literacy involves the ability to understand financial terms and concepts and to translate that knowledge skillfully into behaviour ... Literacy implies knowledge of the terms, practices, laws, rights, social norms, and attitudes needed to understand and perform ... vital financial tasks. It also includes the fact that being able to read and apply basic math skills is essential to making wise financial choices.

Schagen's (1997) UK report for the National Foundation for Education Research (NFER) defines financial literacy as 'the ability to make informed judgements and to take effective decisions regarding the use and management of money' (18).

Nevertheless, problems of definition, and of a well established framework for financial literacy, remain. Some argue that financial literacy should be seen as an essential life skill. Further, the place of numeracy in relation to financial literacy is not well defined; although most definitions incorporate elements of numeracy.

Various studies from the US have measured the benefits of improved levels of adult financial literacy gained through work-based financial education programs or through high school-based programs. A few studies have extended this to look at the return on investment to employers of investing in work-based financial literacy programs (for example, Garman 1998). Research relating to costs and benefits focuses substantially on those who are employed; few studies explore in detail costs and benefits of financial literacy for unemployed people.

The most robust approaches to measuring the benefits of investing in financial education include the utilisation of pre and post-test designs, together with the use of control groups who do not receive financial education.

Important measurement issues include: accounting for the interaction between financial literacy and low income (for example, lack of income/ease of budgeting, or forcing people to choose the more expensive payment option for electricity), as well as the influence of attitudinal, psychological and 'lifestyle' factors, and different life stages. 
Areas where current research is limited include the relationship among the financial literacy levels of employees and general literacy and numeracy skills, their impact on employees and employers, and the impact of financial literacy levels on physical and mental health.

In Australia, research for the ANZ Bank (Roy Morgan Research 2003) and for the Commonwealth Bank (Commonwealth Bank Foundation 2005) surveyed literacy levels within the population. Two reports include estimates of costs of poor financial literacy. The Consumer and Financial Literacy Taskforce (Commonwealth of Australia 2004) modelled the effects of 'bad' financial decision making over the course of a person's life. The Commonwealth Bank Foundation's (2005) study modeled the effects of improving financial literacy levels on individuals and the economy. The increase modeled was a relatively modest target, that is improving the scores of the ten percent of the population with the lowest levels of financial literacy on the financial literacy questionnaire, over a period of ten years. It was estimated that this would increase the average annual income of people with the lowest ten percent of scores by $\$ 3,204$, increase Australia's GDP by $\$ 6$ billion and create 16,000 new jobs. It was also estimated that improving the financial literacy of this group would reduce the incidence of persistent sleeping difficulty amongst the Australian population by two percent and the incidence of regular smoking by two percent.

\section{Business, employers and employees}

There is a sizeable literature that demonstrates the positive returns to employers of investing in workforce training generally (that is improvements in firm productivity and in some cases higher levels of innovation and/or better financial performance); however studies that focus on costs and benefits of literacy and numeracy are far fewer.

Studies (for example, Spilsbury cited in Ananiadou, Jenkins and Wolf 2003) suggest that it is the larger companies that are making the most investment in work-based training in this area. Further, UK studies suggest that most small business employers are largely unaware of poor literacy and numeracy skills (Atkins and Marchant 2004). These findings complement earlier Australian research (Long 1990). We would suggest, however, that small business, which includes self-employed individuals, is an area where costs and benefits of literacy and numeracy are very important. While there is an obvious link between financial literacy and small business, the importance of broad literacy and numeracy skills is equally important.

We did not identify any directly relevant studies examining costs and benefits of literacy and numeracy to small business (employers and employees). However, some of the methodologies used in examining larger enterprises are likely to be useful, although our consultations suggested that the small business sector differs in significant ways from larger enterprises. 
These differences need to be taken account of in any research. Flexible and multiple approaches are likely to be most useful.

Methodologies used to measure the benefits of improving literacy and numeracy amongst the workforce have typically focused on cost savings and/or productivity gains to the company, although some studies looked more widely and included employee focused outcomes such as levels of promotion and rates of absenteeism. The issues of ideal methodologies based on large datasets (panel data is the most ideal) versus achievable methodologies based on availability of data, and the costs of new data collection are important considerations.

Relatively few studies include measures of factors that impact directly on employees, and indirectly influence company profits, that is through employees' job satisfaction, internal promotion, absenteeism, access and take-up of further training and education.

In Australia, while workplace education and the skills of workers has received considerable attention, the most directly relevant study is that by Pearson (1996). He found that language and literacy training was considered to have had a positive effect on five aspects of the workplace: direct cost savings, access to and acceptability of further training, participation in teams and meeting, promotion and job flexibility, and the value of training (which included issues such as worker morale, confidence to communicate, etc.). The study included respondents' quantitative estimate of savings to their companies based on the positive impacts identified.

\section{Family literacy}

To date, there have been no research studies in Australia that have measured the costs of poor family literacy, although there are a fairly large number of studies which have measured the benefits to adults and/or children from participating in family learning programs. Many of the measures used to assess benefits have focused on outcomes such as changes in confidence and attitudes towards literacy and learning by adults and children, or have focused on reading gains (for example, Brooks, Gorman, Harman, Hutchison, Kinder, Moor and Wilkin 1997).

The few studies that have managed to measure a wider range of benefits have tracked parents and/or children over time, as many of the benefits of family literacy, such as educational and employment gains for adults and educational and developmental gains for children, can only be adequately measured once time has passed.

Longitudinal cohort studies are relatively expensive and require established family literacy programs to be in place so that a sufficient number of participants can be identified and followed-up. These types of programs do not generally exist within Australia. Ideally, the adults and children who had participated in family literacy would be compared against 
a control group who had not. This would further increase the costs of the research.

\section{Grime}

Most studies related to crime have focused on education levels and crime, rather than on literacy and numeracy per se. The basic relationships between poor education and crime, and between learning and crime reduction, are quite strong as indicated in a number of studies that show benefits from prison education programs. The few studies reviewed (Hull, Forrester, Brown, Jobe and McMullen 2000, Feinstein 2002, ProLiteracy America 2003) which have focused on literacy and numeracy are promising and show the benefits of decreased recidivism and individual costs, such as a greater likelihood of being picked up repeatedly by police.

There are, nevertheless, inherent difficulties in investigating the relationship between literacy and numeracy and crime, because of the complexity of the individual, social and cultural factors that contribute to crime and the diversity of illegal activities subsumed under the term 'crime'. All of these factors make the measurement of benefits and costs difficult. Further, there is an unknown amount of 'hidden crime' that is rarely taken account of in studies. Data to adequately assess benefits and costs are rarely available.

\section{Taking measurement of costs and benefits forward in Australia}

Our study concluded that there is sufficient interest and a small research base in Australia for obtaining better information about social and economic costs and benefits in relation to health literacy, financial literacy, and literacy and numeracy and small business. There is quite a strong interest in financial literacy from the Commonwealth government and from financial institutions. Health literacy does not, at present, have any obvious champions but some researchers are working in the area. Overseas research has established the link between health literacy and improved health outcomes, and the general level of government and community interest could change in light of ongoing concerns about rising health care costs. As we suggest above, there is a strong case to be made for the importance of literacy and numeracy in relation to small business, and there is some evidence of interest in the area.

The consultations for the project clearly suggested that developing useful research depends on a number of things. Firstly, there is a need to convince government and other research funding bodies that the issue of adult literacy and numeracy costs and benefits is an important individual, community and national issue. Secondly, getting commitment from researchers and others in each of the three selected areas is essential. 
Thirdly, realistic and viable means of taking research forward through partnerships between the adult literacy and numeracy fields, people working in the three sectors, and researchers with particular expertise in modelling and longitudinal study research must be found.

To take forward a research agenda, it is suggested that:

- $\quad$ small, collaborative, cross-discipline working groups are established to obtain agreement on priorities and appropriate methodologies and to jointly seek funding for further research;

- the possibility of 'buying in' to existing Australian longitudinal studies is further explored in order to measure the range of social and economic costs associated with literacy and numeracy;

- further targeted consultations are undertaken to reach a wider range of people in regard to health literacy, financial literacy and literacy and small business;

- the diverse research findings in the report, and the possibilities shown by the overseas research, are widely disseminated;

- $\quad$ steps are taken to ensure the best strategic use of information from the forthcoming Adult Literacy and Lifeskills Survey (ALLS), for example, carefully considering the scope of the sample and the demographic information collected; wide promotion of the potential uses of the ALLS dataset; exploring the possibility of using the MONASH model of the Australia economy in conjunction with the ALLS to model costs and benefits; and planning for a separate analysis of numeracy data from the ALLS.

More broadly, collaboration across sectors and research partnerships is crucial to take forward the assessment and measurement of social and economic costs and benefits associated with literacy and numeracy. There is considerable scope for a range of small and larger research undertakings in health literacy, financial literacy, and literacy and numeracy and small business The uncharted nature of research into benefits and costs associated with multiple literacies in Australia, together with what has been learnt from the diverse overseas literature, leaves the way open for some focused initiatives which could ultimately contribute to a broader understanding of the social and economic costs and benefits of literacy and numeracy and to strong policy development.

\section{Endnote}

1 This article is based on a paper prepared for 'Connecting Voices:

Practitioners, researchers and learners', Adults Learning Mathematics 
(ALM) 12 conference sponsored by ALM and the Australian Council for Adult Literacy, Melbourne, July 4-7, 2005.

\section{References}

Ananiadou, K, Jenkins, A and Wolf, A (2003) The Benefits to Employers of Raising Workforce Basic Skills Levels: A review of the literature, National Research and Development Gentre for Adult Literacy and Numeracy, London.

Atkin, C and Marchant, P (2004) The Impact of Adult Literacy and Numeracy on Small Businesses in Rural Lincolnshire and Rutland: A case study, National Research and Development Gentre for Adult Literacy and Numeracy, London.

Beddie, F (2004) Community Literacy: A discussion paper, retrieved from www.dest.gov.au/literacynet/

Berkman, N, DeWalt, D, Pignone, M, Sheridan, S, Lohr, K N, Lux, L, Sutton, S F, Swinson, T and Bonito, A J (2004) Literacy and Health Outcomes, Evidence report/technology assessment No. 87, Prepared by RTI International-University of North Carolina Evidence-based Practice Center under Contract No. 290-02-0016), AHRQ

Publication No. 04-E007-2, Agency for Healthcare Research and Quality, Rockville, MD January.

Brooks, G, Gorman, T, Harman, J, Hutchison, D, Kinder, K, Moor, H and Wilkin, A (1997) Family Literacy Lasts: The National Foundation for Educational Research follow-up study of the Basic Skills Agency demonstration programs, Basic Skills Agency, London.

Buchbinder, R, Hall, S, Grant, G, Mylvaganam, A and Patrick, M (2001) Readability of Content and Supplementary Written Drug Information for Patients Used by Australian Rheumatologists, Medical Fournal of Australia, vol 174, no 11, pp 557-8.

Bynner, J, McIntosh, S, Vignoles, A, Dearden, L, Reed, H and van Reenen, J (2001) Improving Adult Basic Skills: Benefits to the individual and society, Department for Education and Skills, London.

Chiswick, B R, Lee, Y L and Miller, P W (2003) Schooling, Literacy, Numeracy and Labour Market Success, The Economic Record, vol 79, no 245, pp 165-181.

Commonwealth of Australia (2004) Australian Consumers and Money: A discussion paper by the Consumer and Financial Literacy Taskforce, Commonwealth of Australia, Canberra.

Commonwealth Bank Foundation (2005) Improving Financial Literacy in Australia: Benefits for the individual and the nation, Commonwealth Bank Foundation, Eureka Strategic Research and Centre of Policy Studies, Monash University, Melbourne. 
Coulombe, S, Tremblay, J-F and Marchand, S (2004) Literacy Scores, Human Capital and Growth across Fourteen OECD Countries, Statistics Canada and Human Resources and Skills Development Canada, Catalogue no 89-552-MIE.

Desjardins, R (2004) Learning for Well-being: Studies using the International Adult Literacy Survey, Studies in Comparative and International Education 65, Institute of International Education, Stockholm University, Stockholm.

Feinstein, L (2002) Quantitative Estimates of the Social Benefits of Learning, 1: Crime, Research Report No. 5, Centre for Research on the Wider Benefits of Learning, London.

Garman, T (1998) The Business Case for Financial Education: Personal financial wellness and employee productivity, Personal Finances and Worker Productivity, vol 2, no 1, pp 81-93.

Gillis, D and Quigley, A (2004) Taking Off the Blindfold: Seeing how literacy affects health, A report of the Health Literacy in Rural Nova Scotia Research Project, St Francis Xavier University, Nova Scotia, Canada.

Gleeson, J (2005) Economic Returns to Education and Training for Adults with Low Numeracy Skills, National Centre for Vocational Education Research, Adelaide.

Griffin, J, McKenna, K and Tooth, L (2003) Written Health Education Material: Making them more effective, Australian Occupational Therapy Fournal, vol 50, no 3, pp 170-177.

Hagston, J (2002) Exploring the International Adult Literacy Survey data: Implications for Australian research and policy, Language Australia Publications, Melbourne

Hartley, R (1989) The Social Costs of Inadequate Literacy, A report for International Literacy Year, Australian Government Publishing Service, Canberra.

Hartley, R and Horne, J (2006) Social and Economic Benefits of Improved Adult Literacy: Towards a better understanding, National Centre for Vocational Education Research, Adelaide.

Hull, K, Forrester, S, Brown, J, Jobe, D and McMullen, C (2000) Analysis of Recidivism Rates for Participants of the Academic/Correctional/Transition Programs offered by the Virginia Department of Correctional Education, Fournal of Correctional Education, vol 51, no 2, cited in ProLiteracy America 2003.

Jacob, K, Hudson, S and Bush, M (2000) Tools for Survival: An analysis of finanacial literacy programs for lower-income families, Woodstock Institute, 407 S. Dearborn, Chicago, Ill.

Long, P (1990) Workforce Perceptions of Literacy and Multi-skilling Issues, Open Letter, Australian Fournal for Adult Literacy and Research, vol 1, no 1, pp 18-29. 
Lonsdale, M and McCurry, D (2004) Literacy in the New Millennium, National Centre for Vocational Education Research, Adelaide.

Marks, G and Fleming, N (1998) Factors Influencing Youth Unemployment in Australia, Longitudinal Surveys of Australian Youth, vol 7, September, pp 1-47.

Miltenyi, G (1989) English in the Workplace: A shrewd investment?, Summary, prepared by Eyles Miltenyi Davids Pty Ltd, for the Office of Multicultural Affairs, Department of Prime Minister and Cabinet, Canberra.

Moy, J and McDonald, R (2000) Analysing Enterprise Returns on Training, National Centre for Vocational Education Research, Adelaide

Nutbeam, D (1999) Literacies Across the Life Span: Health literacy, Literacy and Numeracy Studies: An international journal in the education and training of adults, vol 9, no 2, pp 47-55.

Organisation for Economic Cooperation and Development (OECD) and Statistics Canada (2000) Literacy in the Information Age: Final report of the International Adult Literacy Survey, Organisation for Economic Cooperation and Development, Paris, and the Minister of Industry, Canada.

Pearson, G (1996) More Than Money Can Buy: The impact of ESL and literacy training in the Australian workplace, Department of Employment, Education, Training and Youth Affairs, Canberra.

ProLiteracy America (2003) US Adult Literacy Programs: Making a difference, a review of research on positive outcomes achieved by literacy programs and the people they serve, ProLiteracy Worldwide, Syracuse, NY.

Roberts, P and Fawcett, G (1998) At Risk: A socio-economic analysis of health and literacy among seniors, International Adult Literacy Survey, Statistics Canada, Human Resources Development Canada and National Literacy Secretariat, Catalogue no 89-552-MPE, no 5.

Rootman, I and Ronson, B (2003) Literacy and Health Research in Canada: Where have we been and where should we go?, National Literacy and Health Research Project, retrieved from www.nlhp.ca.

Roy Morgan Research (2003) ANZ Survey of Adult Financial Literacy in Australia - Final report, retrieved on 20 February 2007 from www.anz.com.au/aus/aboutanz/Community/Programs/FinSurvey2 005.asp\#adult.

Schagen, S (1997) The Evaluation of NatWest Face 2 Face with Finance, National Foundation For Education Research, London.

Schuller, T Bynner, J Green, A Blackwell, L Hammond, C Preston, J and Gough, M (2001) Modelling and Measuring the Wider Benefits of Learning: A synthesis, Institute of Education, University of London. 
Schuller, T, Preston, J, Hammond, C, Brassett-Grundy, A and Bynner, J (2004) The benefits of Learning: The impact of education on health, family life and social capital, Routledge Falmer, London.

Shohet, L (2004) Health and Literacy: Perspectives, Literacy and Numeracy Studies: An international journal in the education and training of adults, vol 13, no1, pp 65-83.

Singh, S (1989) The hidden costs of illiteracy, Business Review Weekly, June, p. 72-74.

Wickert, R (2004) Everyone's Responsibility: Towards meeting the adult language, literacy and numeracy needs of a modern Australia. Retrieved from www.dest.gov.au/literacynet/

Williams, M, Parker, R, Baker D, Parikh, N, Pitkin, K, Coates, W and Nurss, J (1995) Inadequate Functional Health Literacy Among Patients at Two Public Hospitals, Journal of the American Medical Association, vol 274, pp 1677-1682. 